Research, Society and Development, v. 9, n. 9, e611997801, 2020

(CC BY 4.0) | ISSN 2525-3409 | DOI: http://dx.doi.org/10.33448/rsd-v9i9.7801

Atividades práticas de Biologia: uma Sequência de Ensino Investigativa sobre o Ciclo Celular

Practical Biology activities: an Investigative Teaching Sequence about the Cell Cycle Actividades practicas de Biología: una Secuencia de Enseñanza Investigative sobre el

\title{
Ciclo Celular
}

Recebido: 21/08/2020 | Revisado: 24/08/2020 | Aceito: 29/08/2020 | Publicado: 01/09/2020

Michelle Mara de Oliveira Lima

ORCID: https://orcid.org/0000-0001-6522-8477 Instituto Federal de Educação, Ciência e Tecnologia do Piaú́, Brasil

E-mail: michellelima@ifpi.edu.br Thâmara Chaves Cardoso ORCID: https://orcid.org/0000-0002-2164-6746 Universidade Estadual do Piauí, Brasil E-mail: thamarachavescardoso@gmail.com Francisco Soares Santos Filho ORCID: https://orcid.org/0000-0002-1713-7228 Universidade Estadual do Piauí, Brasil E-mail: fsoaresfilho@gmail.com Francielle Alline Martins ORCID: https://orcid.org/0000-0002-0113-8023 Universidade Estadual do Piauí, Brasil E-mail: franufv@yahoo.com.br

Pedro Marcos de Almeida ORCID: https://orcid.org/0000-0001-5431-6818 Universidade Estadual do Piauí, Brasil pedromarcosalmeida@yahoo.com.br

\section{Resumo}

O objetivo do estudo foi desenvolver e analisar o uso de uma Sequência de Ensino Investigativa (SEI) sobre o ciclo celular (mitose), composta por um modelo didático e pela prática de Allium cepa L. com estudantes de duas escolas públicas e uma particular em Floriano (PI). Mediante as respostas às problematizações da SEI verificou-se que os 
estudantes possuíam conhecimentos desconexos e fragmentados quanto ao conteúdo do ciclo celular. A aplicação da SEI modificou a postura dos alunos das três escolas, que passaram a ser mais participativos entre si e com a professora, corroborando com os dados obtidos da comparação dos questionários pré e pós-teste. As metodologias ativas aplicadas foram satisfatórias e tiveram ótima aceitação pelos estudantes. Portanto, constatou-se que o uso da SEI facilitou a compreensão da dinâmica que envolve o ciclo celular e suas implicações para a constituição dos seres vivos, minimizando o distanciamento entre a teoria e a prática.

Palavras-chave: Metodologia Ativa; Mitose; Modelo didático; Allium cepa L.

\begin{abstract}
The aim of this study was to develop and to analyze the use of an Investigative Teaching Sequence (ITS) about the cell cycle (mitosis), composed by a didactic model and by a practical class with Allium cepa L. with students from two public schools and from a particular one in Floriano (PI). Through the answers to the questioning of ITS, it was found that the students had disconnected and fragmented knowledge about the content of the cell cycle. The ITS application modified the attitude of the students of the three schools, which became more participative among themselves and with the teacher, corroborating with the data obtained from the comparison of pre and post-test questionnaires. The applied active methodologies were satisfactory and had great acceptance by the students. Therefore, it was found that the use of ITS facilitated the understanding of the dynamics surrounding the cell cycle and its implications for the constitution of living beings, minimizing the distance between theory and practice.
\end{abstract}

Keywords: Active Methodology; Mitosis; Didactic model; Allium cepa.

\title{
Resumen
}

El objetivo del estúdio fue desarrollar y analizar el uso de uma Secuencia de Enseñanza Investigativa (SEI) sobre el ciclo celular (mitosis), compuesta por um modelo didáctico y la práctica de Allium cepa L. con estudiantes de dos escuelas públicas y uma privada em Floriano (PI). Através de las respuestas a las problematizaciones de SEI, se encontro que los estudiantes tenían conocimentos desconectados y fragmentados sobre el contenido del ciclo celular. La aplicación del SEI modicicó la postura de los estudiantes de las três escuelas, quienes se volvieron más participativos entre ellos y com el docente, corroborando com los dados obtenidos de la comparación de los cuestionarios pre y post test. Las metodologias 
activas aplicadas fueron satisfactorias y tuvieron gran aceptación por parte de los estudiantes. Por tanto, se encontro que el uso de SEI facilitó la comprensión de la dinâmica que envuelve el ciclo celular e sus implicaciones para la construción de los seres vivos, minimizando la becha entre teoria y práctica.

Palabras clave: Metodología activa; Mistosis; Modelo didáctico; Allium cepa L.

\section{Introdução}

O ensino de Biologia deve permitir a compreensão das relações existentes entre os seres vivos e não vivos, estimulando discussões e debates no contexto escolar e social a partir da aquisição do conhecimento científico. No entanto, os estudantes geralmente apresentam dificuldades na aprendizagem dessa disciplina, por possuir uma variedade de terminologias e temas em nível molecular, o que dificulta a consolidação do conhecimento, além de estarem desvinculados de suas realidades (Duré, et al., 2018; Pereira \& Miranda, 2017). A prática docente na disciplina de Biologia tem sido pautada, principalmente, na racionalidade técnica, onde é priorizada a mera transmissão dos conteúdos, sem propiciar a interação do professor com os estudantes, e dos estudantes entre si no processo de ensino-aprendizagem (VinholiJúnior \& Princival, 2014). Assim, torna-se relevante que haja modificações nos processos metodológicos utilizados pelo professor, tendo em vista a estimular a participação dos estudantes na construção do conhecimento.

Uma das áreas que apresenta maior dificuldade de aprendizado é a Biologia Celular devido à presença de termos e processos que estão relacionados às dimensões microscópicas, como o ciclo celular (Pereira \& Miranda, 2017). Este tópico exige a compreensão da composição e a função de cada estrutura presente na célula durante todas as fases do ciclo. Contudo, os estudantes não conseguem ou apresentam muitas dificuldades em relacionar as estruturas às suas respectivas funções em cada fase do ciclo e não compreendem a importância deste evento para a manutenção da vida (Moul \& Silva, 2017). Estes fatos estão associados principalmente com a abstração do conteúdo do ciclo celular e dificuldades de relacionar com o cotidiano dos estudante (Kieling, et al., 2018).

Neste contexto, na tentativa de melhorar o ensino e de estimular a participação e a integração dos estudantes na construção do conhecimento, vários estudos buscam incorporar estratégias de ensino como as metodologias ativas (MA) (Borges \& Alencar, 2014; Garofalo, 2018; Krug, et al., 2016; Macedo, et al., 2018). As MA são consideradas como abordagens crítico-reflexivas utilizadas no processo de aprendizagem com intuito principal de estimular a 
participação do aluno na construção do conhecimento (Macedo, et al., 2018). Os pressupostos construtivistas presentes em MA são embasados na Teoria da Aprendizagem Significativa, proposta por David Ausubel (1918-2008), que afirma que é necessária a mobilização dos conhecimentos prévios dos alunos de forma a despertar o seu interesse para o conteúdo. A aprendizagem significativa acontecerá quando os conceitos se mostrarem relevantes e aplicávebis à cognição do aluno de forma que o permita estabelecer conexões entre os conteúdos aprendidos (Ausubel, 2003; Tanajura, 2017).

Segundo Garofalo (2018) a utilização de MA na sala de aula faz com que os alunos modifiquem a sua maneira de pensar de forma que seja possível solucionar problemas a partir do desenvolvimento de habilidades especificas, como autonomia, aptidão em resolver problemas, colaboração, confiança, protagonismo, senso crítico, aprendizagem envolvente, empatia, responsabilidade e participação. Dentre as MA, pode-se destacar a Aprendizagem Baseada em Problemas, que visa à construção do aprendizado mediante a busca pela solução, que podem ser resolvidos de forma investigativa (Garofalo, 2018). Segundo Scarpa e Campos (2018), o ensino por investigação deve ter como princípio norteador, o uso de estratégias didáticas que tenham o intuito primordial de envolver ativamente os estudantes na resolução de questões e problemas, em que a reflexão, a análise e a discussão sejam condições para solucioná-los. Desta forma, o professor pode selecionar modelos lúdicos e/ou práticas que possam integrar sequências de ensino que promovam o ensino investigativo com o objetivo de alcançar uma aprendizagem significativa.

Modelos didáticos são metodologias de ensino eficazes no ensino de biologia celular, auxiliando na aprendizagem de conceitos e processos abstratos (Gonçalves, et al., 2014; Porto, et al., 2015). Muitos autores utilizam estes modelos para minimizar as dificuldades encontradas pelos estudantes na compreensão do ciclo celular (Braga, et al., 2010; Luo, 2012, Moul \& Silva, 2017, Silva, et al., 2018). Entretanto, a aplicação desta metodologia dentro de uma perspectiva investigativa ainda é incipiente na literatura. Aulas práticas são metodologias de ensino que despertam a curiosidade dos estudantes e são estratégias que favorecem a observação e a investigação de fenômenos biológicos. Para o ciclo celular, autores como Wons (2012), Cobalchini (2016) e Fernandes et al. (2017) propõem a utilização da prática de Allium cepa L. (cebola) como metodologia de ensino sobre mitose apenas como manuais de aulas práticas. Enquanto, estudos científicos sobre a utilização dessa prática com estudantes foram relatados apenas por Carneiro e Silva (2007) com alunos de graduação, Barbosa (2015) com alunos da Educação de Jovens e Adultos (EJA) e Kieling et al. (2018) com alunos do ensino médio, que mostraram a importância da prática na compreensão do ciclo celular. 
Contudo, a utilização de $A$. cepa na educação básica ainda é incipiente a partir de uma perspectiva investigativa.

Sendo assim, considerando a importância de utilizar metodologias de ensino que estimulem os estudantes a analisar e refletir sobre problemas propostos para a construção do conhecimento, o objetivo deste estudo foi desenvolver uma Sequência de Ensino Investigativa (SEI) sobre o ciclo celular utilizando um modelo didático e células meristemáticas de A. cepa como metodologias de ensino, bem como avaliar a sua utilização com estudantes de duas escolas públicas, sendo uma Federal e outra Estadual e uma escola Particular em Floriano-PI.

\section{Metodologia}

\subsection{Caracterização da Amostra}

A pesquisa foi aprovada pelo Comitê de Ética em Pesquisa (CEP-UESPI 2.609.879) e realizada com 63 estudantes, que estavam cursando o componente curricular de Biologia do terceiro ano do Ensino Médio em três escolas (21 estudantes por escola), do município de Floriano (PI), sendo duas escolas públicas, uma Federal (EF) e uma Estadual (EE); e uma Escola Particular (EP). A aplicação de cada uma das etapas que compõem este estudo ocorreu durante dois dias, por escola, sendo $3 \mathrm{~h}$ /aula no primeiro dia e $5 \mathrm{~h} /$ aula no segundo, nos meses de junho na EF, agosto na EP e novembro na EE em 2018. Do total de 8 h/aula destinados para a realização desta pesquisa em cada escola, 6h/aula foram utilizadas para a aplicação da SEI.

\subsection{Instrumento de coleta de dados}

Os dados para a pesquisa foram coletados a partir de um questionário com 14 questões (7 subjetivas e 7 objetivas). O questionário foi aplicado em duas etapas distintas: A primeira antes da utilização da SEI (pré-teste) e a segunda após a utilização da SEI (pós-teste) em cada uma das escolas. As questões subjetivas foram compostas por: um esquema para o estudante identificar as estruturas celulares que participam do ciclo celular (questão 1); definição de ciclo celular (questão 2); principais características da mitose (questão 3); principais características da intérfase e sua importância para o ciclo celular (questão 4); identificação das fases do ciclo celular a partir da análise de figuras (questão 5); exemplos de 
células que realizam mitose no corpo humano (questão 6) e exemplos de algumas doenças relacionadas à mitose (questão 7).

A avaliação das respostas das questões subjetivas foi realizada segundo Griffin, McMiller, Jones e Johnson (2003), Silva e Andrade Neto (2004) e Carneiro e Silva (2007), com adaptações. As respostas foram avaliadas de forma quantitativa e agrupadas nas seguintes classes: Classe 0 (sem resposta - resposta do tipo não sabe, erradas ou em branco; Classe 1 (resposta pobre/sem informação - respostas que não indicam compreensão do estudante sobre o tema; Classe 2 (resposta fraca/racionalidade e estabelecimento de conexões dos conceitos não satisfatórias - respostas que manifestam certa compreensão dos conceitos, mas sem fundamentação teórica; Classe 3 (resposta satisfatória/racionalidade e estabelecimento de conexões dos conceitos - respostas que demonstram compreensão dos elementos científicos mais importantes e Classe 4 (resposta excelente/racionalidade e estabelecimento de conexões dos conceitos e aplicações - percebe-se a compreensão total sobre a resposta, podendo apresentar refinamento nas respostas e discussões além do que foi questionado).

As questões objetivas foram compostas por perguntas sobre características e/ou estruturas das diferentes fases do ciclo celular como: rompimento do envoltório nuclear (questão 1); duplicação dos cromossomos (questão 2); condensação dos cromossomos (questão 3); migração das cromátides irmãs (questão 4); sequência das fases do ciclo celular (questão 5); formação da placa equatorial (questão 6) e estrutura responsável por promover a ligação dos cromossomos ao fuso mitótico (questão 7). Cada questão objetiva possui apenas uma alternativa correta (nota 1 ) ou nota 0 (zero) para alternativas incorretas ou em branco.

Com o intuito de conhecer a percepção dos estudantes quanto às metodologias empregadas na SEI foi aplicado o questionário feedback com dez perguntas objetivas (cinco para o modelo didático e cinco para A. cepa). Os estudantes avaliaram as metodologias com notas de zero a cinco. As perguntas abordadas foram: nota para a metodologia utilizada; o nível de dificuldade em compreender e executar a atividade proposta; escala de contribuição da metodologia para a aprendizagem do ciclo celular; nível de interesse durante a aplicação da metodologia e nível de satisfação com a metodologia empregada.

\subsection{Aplicação da Sequência de Ensino Investigativa (SEI) sobre o ciclo celular}

A SEI proposta neste estudo foi composta pelas seguintes etapas: Problematização geral; Modelo didático sobre o ciclo celular e Aula prática de A. cepa. Na problematização 
geral, os estudantes foram estimulados a refletir sobre o conteúdo do ciclo celular de um modo geral a partir de questões motivadoras, como: Qual a importância da divisão celular para os seres vivos? Quais estruturas das células participam do processo de divisão celular? De que forma o material genético se divide? Em seguida participaram de uma aula dialogada (1 h) sobre o conteúdo. Neste momento os estudantes expressaram suas percepções sobre as perguntas motivadoras e participaram ativamente das discussões sobre o conteúdo com a professora. Após a exposição dialogada, outras perguntas motivadoras (Qual a importância da eficácia divisão celular para os seres vivos? De que forma as fibras do fuso garantem a eficiência da divisão celular? Como o material genético se organiza para dividir?) foram realizadas para serem analisadas no contexto do modelo didático, o que estimulou a participação e o diálogo entre os grupos e a professora.

Após as reflexões iniciais sobre as questões motivadoras os alunos participaram da montagem do modelo didático. Para a utilização do modelo didático desenvolvido para o presente estudo, os estudantes foram divididos em cinco grupos onde cada um recebeu um kit contendo a peça base e peças de biscuit com as estruturas que participam das fases do ciclo celular (Figura 1).

Figura 1. Peças que compõem o modelo didático. Peça base (verde e branco), envoltório nuclear (azul); cromatina e cromossomos (vermelho e roxo); centrômeros (laranja e azul); centríolos e fuso mitótico (amarelo).

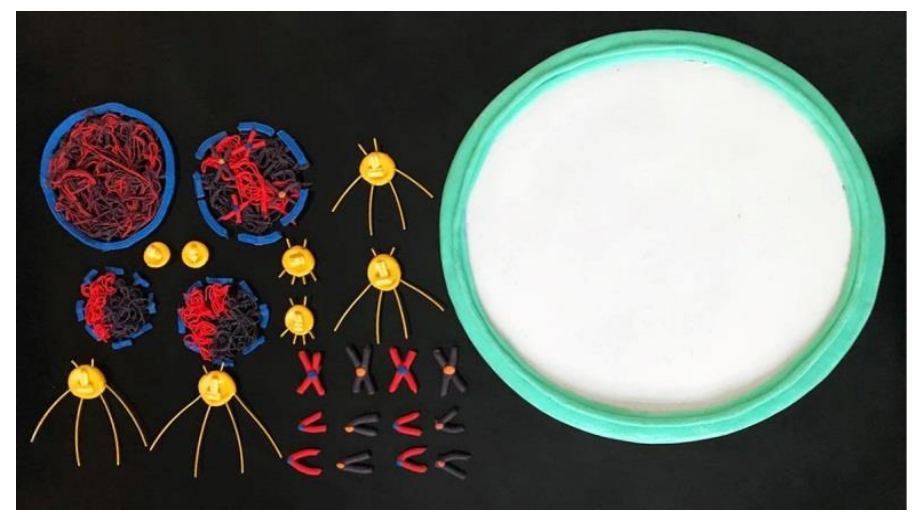

Fonte: Produzido pelos autores (2019).

Em seguida, foi solicitado que os grupos dispusessem as peças de biscuit em cima da mesa para que observassem cada estrutura individual, questionando-se sobre o seu papel nas fases correspondentes. Em seguida, montaram cada uma das fases que caracteriza o ciclo celular, inicialmente de forma sequencial (Figura 2) respeitando a ordem de ocorrência de 
cada uma e, em seguida de forma aleatória, relacionando as estruturas e as funções das peças com suas respectivas fases, para que fosse possível avaliar a correta correlação das peças às suas respectivas funções em cada fase.

Figura 2. Fases do ciclo celular no modelo didático. (A) Intérfase, (B) Prófase, (C) Metáfase, (D) Anáfase, (E) Telófase.

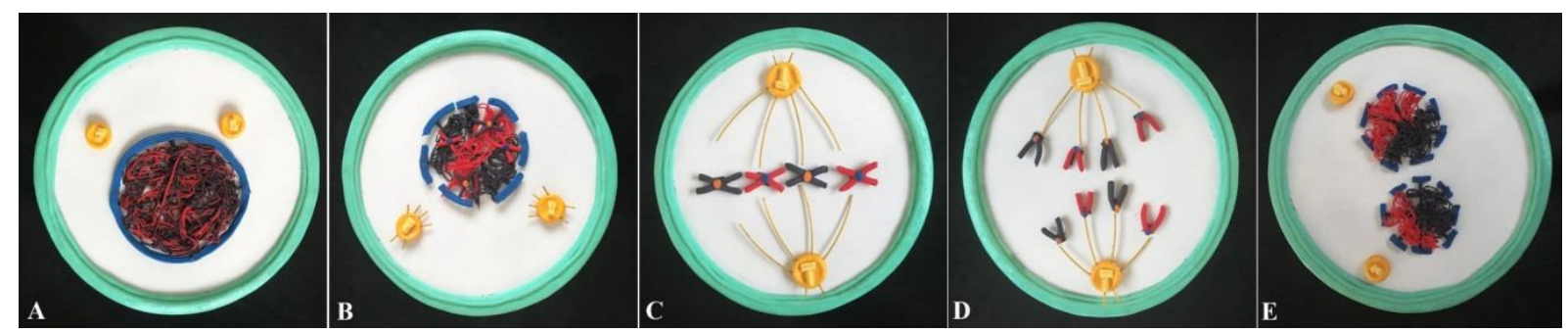

Fonte: Produzido pelos autores (2019).

Na prática A. серa, também foram realizados questionamentos como: Por que utilizar o A. cepa como modelo de estudo? O que está acontecendo na região meristemática da raiz? Por que usar esta região na prática? O que aconteceria se por algum motivo houvesse um erro no controle da divisão celular? Cada uma das fases do ciclo celular se apresenta da mesma forma em todas as células de A. cepa? Os estudantes, de cada escola, foram subdivididos em dois grupos e cada turma realizou uma aula prática de $2 \mathrm{~h}$ no Laboratório de Biologia do IFPI - Floriano. Cada estudante recebeu um roteiro de aula prática e os procedimentos prévios da prática foram explicados aos estudantes durante a realização. Sementes de A. cepa (cv. Vale Ouro IPA-11) foram germinadas em placas de Petri fechadas durante cinco dias em $3 \mathrm{~mL}$ de água de torneira por placa em temperatura ambiente.

Posteriormente, o material foi fixado em Carnoy (3 etanol: 1 ácido acético; v:v) por 6-8 h, à temperatura ambiente, e estocadas à $-20^{\circ} \mathrm{C}$, até o momento da confecção das lâminas (Bianchi, et al., 2015). Em seguida, os estudantes realizaram a confecção das lâminas seguindo a metodologia de Bianchi et al. (2015) com modificações. As raízes foram lavadas três vezes em água destilada, de 5 min cada, e hidrolisadas a $60^{\circ} \mathrm{C}$, por $10 \mathrm{~min}$, em $\mathrm{HCl} 1 \mathrm{~N}$. Após a hidrólise, as raízes foram novamente lavadas em água destilada e transferidas para frascos de vidro âmbar, contendo o Reativo de Schiff, onde permaneceram em local escuro, por $30 \mathrm{~min}$. Após esse período, as raízes foram lavadas, até a total retirada do reativo, transferidas para as lâminas, onde foram esmagadas em uma gota de carmim acético $2 \%$ e montadas com lamínulas. 


\subsection{Análise estatística}

Os resultados dos questionários (pré e pós) de cada turma foram expressos em média e desvio-padrão e os dados foram comparados e analisados pelo teste t de Student $(\mathrm{p}<0,05)$ para dados pareados. As médias dos questionários (pré, pós e feedback) foram comparados entre as escolas pelo teste de Kruskall-Wallis com teste de Student-Newman-Keuls $a$ posteriori $(\mathrm{p}<0,05)$. Ambos os testes foram realizados no programa BioEstat 5.3 (Ayres, et al., 2007). A avaliação do ganho normalizado de aprendizagem $(g$ ) foi realizada a partir da equação proposta por Hake (1998) que permite avaliar o quanto as turmas envolvidas em atividades de aprendizagem progrediram na compreensão de determinado tópico. O $g$ é categorizado em três classes: baixo $(g<0,30)$, médio $(0,30 \leq g<0,70)$ e alto $(g \geq 0,70)$ e é definido pela equação:

$$
g=\frac{\% \text { pós }-\% \text { pré }}{100-\% \text { pré }}
$$

\%pós = percentual de acertos do estudante no pós-teste.

\%pré = percentual de acertos do estudante no pré-teste.

\section{Resultados e Discussão}

A partir da análise das concepções prévias referentes à problematização geral da SEI, os estudantes mostraram dificuldades em compreender como o material genético se divide, a dinâmica dos eventos e as estruturas celulares participantes do ciclo celular, corroborando com os resultados encontrados no pré-teste das questões subjetivas e objetivas (Figura 3). Quando foi realizada a comparação do pós-teste com o pré-teste de cada escola, houve um aumento significativo na média individual e total das questões subjetivas (Figura 3 ABC) e objetivas (Figura 3 DEF) do pós-teste nas três escolas. Este resultado reforça a importância do uso de MA como as que compõem a SEI para desenvolver com os estudantes as habilidades de analisar e de buscar a resolução de problemas, viabilizando a apropriação de conceitos, além de tornar a aula mais dinâmica, interativa e participativa (Leão \& Randi, 2017). 
Figura 3. Média comparativa das respostas do pré-teste com o pós-teste das questões subjetivas (A, B e C) e objetivas (D, E e F) realizadas por 21 alunos das EF, EE e EP na cidade de Floriano-PI.

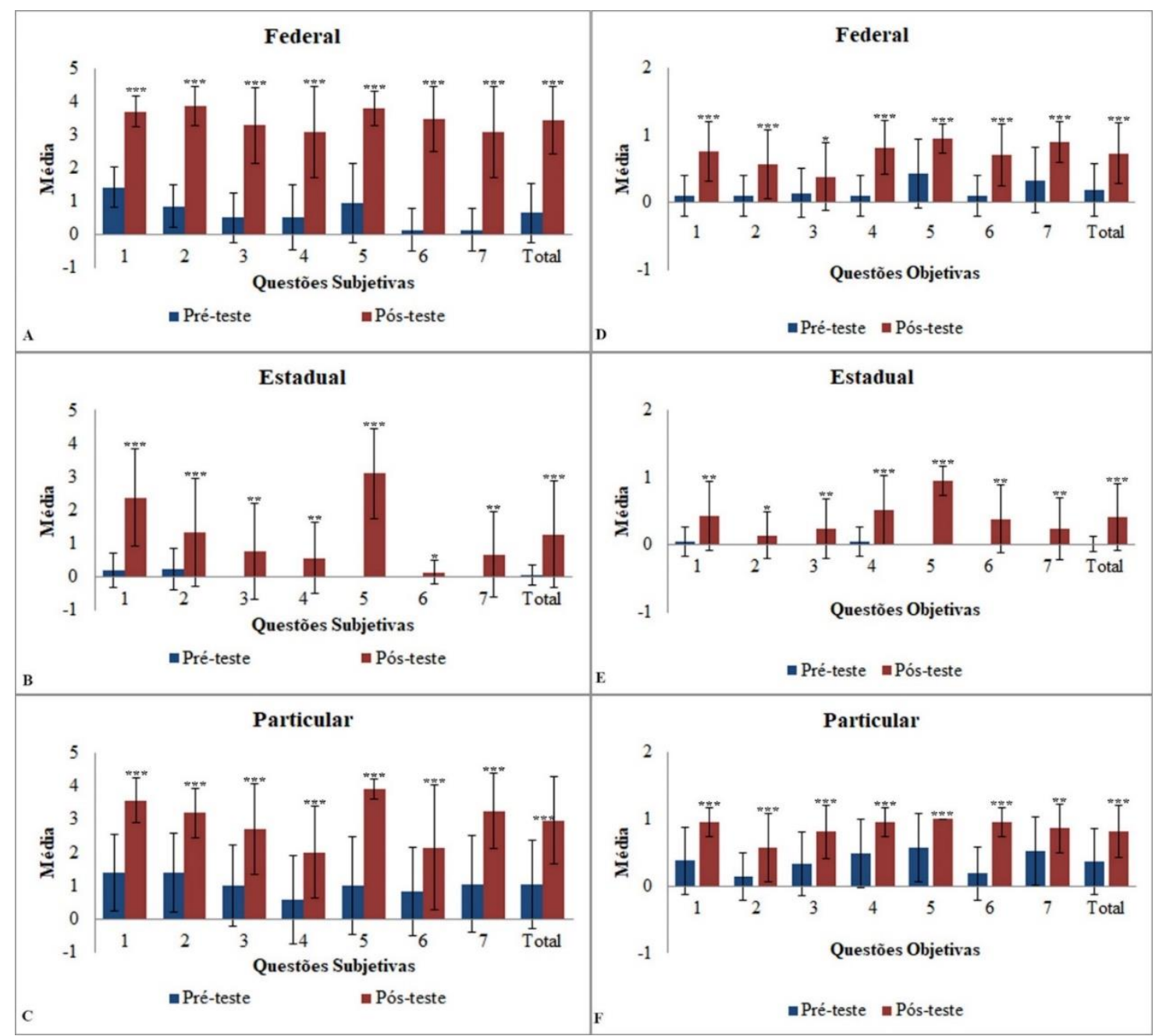

* Significativo no teste $t$, para dados pareados $(* * * p<0,001),(* * p<0,01),(* p<0,05)$. As médias do pós-teste foram comparadas com o pré-teste. Questões Subjetivas: 1 - esquema das estruturas celulares participantes do ciclo celular; 2 - definição de ciclo celular; 3 - características da mitose; 4 - características da intérfase e sua importância para o ciclo celular; 5 - fases do ciclo celular a partir da análise de figuras; 6 - células que realizam mitose no corpo humano e 7 - doenças relacionadas à mitose. Questões objetivas 1- fase do rompimento do envoltório nuclear; 2 - fase da duplicação dos cromossomos; 3 - fase da condensação dos cromossomos; 4 estrutura envolvida na migração das cromátides irmãs; 5 - sequência das fases do ciclo celular; 6 - fase da formação da placa equatorial e 7 - estrutura responsável por promover a ligação do fuso mitótico aos cromossomos.

Fonte: Dados da pesquisa (2019).

A análise das respostas do pré-teste das questões subjetivas (Figura 4 A) evidenciou os melhores resultados para todas as questões da EF e da EP. Destacando as médias significativas nas questões 1, 2, 5 e na média total da EF e na maioria das questões $(1,2,3,5$, 7) e no total da EP. Enquanto a EP apresentou melhores resultados na maioria das questões, sendo significativa apenas na questão 7 em relação à EF. Resultados similares foram 
observados para as questões objetivas do pré-teste (Figura 4 B), com médias significativas na questão 5 e no total da EF e nas questões 5 e 7 e no total da EP. Entre a EF e a EP, a média total foi significativa para os estudantes da EP, uma vez que estes estudantes apresentaram médias maiores para todas as questões.

Figura 4. Média das respostas do pré-teste das questões subjetivas (A) e objetivas (B) e do pós-teste das questões subjetivas (C) e objetivas (D) realizadas por 21 estudantes das escolas Federal, Estadual e Particular na cidade de Floriano-PI.

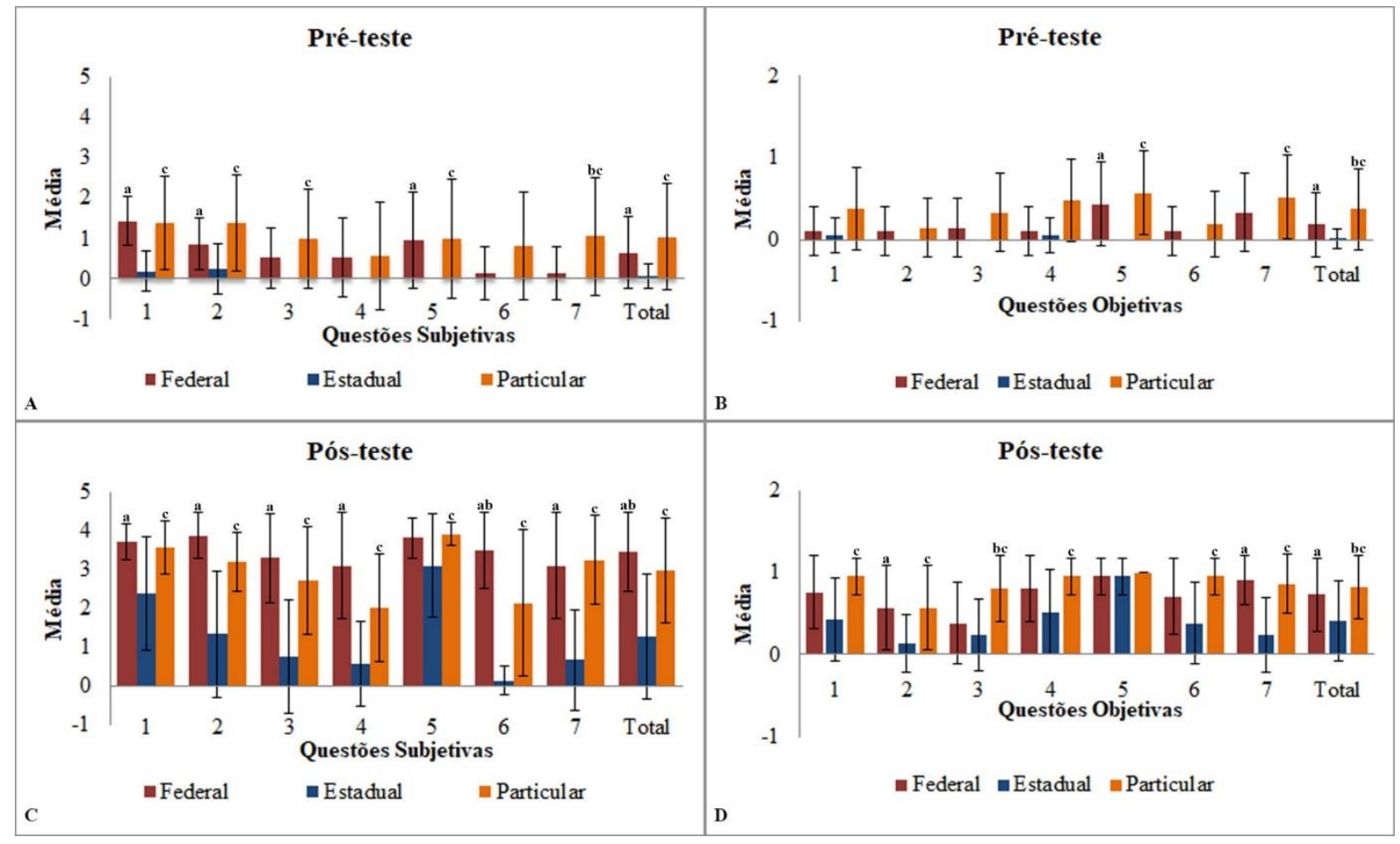

a,b,c Significativo no teste de Kruskall-Wallis com teste de Student-Newman-Keuls a posteriori $(\mathrm{p}<0,05){ }^{\text {a }}$ média da Federal comparada com a Estadual, ${ }^{\mathrm{b}}$ média da Federal comparada com a Particular $\mathrm{e}^{\mathrm{c}}$ média da Particular comparada com a Estadual. Questões Subjetivas: 1 - esquema das estruturas celulares participantes do ciclo celular; 2 - definição de ciclo celular; 3 - características da mitose; 4 - características da intérfase e sua importância para o ciclo celular; 5 - fases do ciclo celular a partir da análise de figuras; 6 - células que realizam mitose no corpo humano e 7 - doenças relacionadas à mitose. Questões Objetivas: 1- fase do rompimento do envoltório nuclear; 2 - fase da duplicação dos cromossomos; 3 - fase da condensação dos cromossomos; 4 estrutura envolvida na migração das cromátides irmãs; 5 - sequência das fases do ciclo celular; 6 - fase da formação da placa equatorial e 7 - estrutura responsável por promover a ligação do fuso mitótico aos cromossomos.

Fonte: Dados da pesquisa (2019).

De forma geral, observou-se que no pré-teste a EP obteve as melhores médias para as questões subjetivas e objetivas e a EE apresentou menor desempenho nas questões subjetivas, por possuir maior quantidade de respostas presentes na classe/nota 0 , e nas objetivas com a maior porcentagem de erros. O melhor desempenho dos alunos da EP pode estar relacionado à presença de três disciplinas de Biologia (I, II e III) que são lecionadas de forma 
concomitante, com carga horária de 2h/aula cada, totalizando 6h/a para a disciplina Biologia durante o terceiro ano do Ensino Médio. Enquanto, a EF e a EE possuem somente uma disciplina com os conteúdos de Genética, Evolução e Ecologia com carga horária total de 3 h/aula em cada uma das escolas.

Os estudantes da EF, mesmo apresentando apenas uma disciplina, tiveram melhor desempenho, reforçando que este resultado pode estar associado ao fato dos alunos da EF já terem passado por uma seleção para ingressar na instituição, e também devido à melhor infraestrutura, maior estímulo e qualificação dos docentes tanto nos Institutos Federais como nas Particulares, como relatado por Ramos (2017). Ainda segundo a autora, o desempenho dos estudantes de escolas Federais tende a ser igual ou superior aos de escolas Particulares. Enquanto as redes municipais e estaduais apresentam resultados abaixo da média nacional. Monteiro e Silva (2015) afirmaram que é necessário investir em políticas públicas que forneçam subsídios de instalações e materiais de qualidade, além de valorizar o papel do professor, de forma a incentivá-lo a buscar por qualificação para garantir um ensino de qualidade.

Mesmo nas escolas com melhor desempenho (EP e EF) no pré-teste, verificou-se que os estudantes apresentavam conhecimentos fragmentados sobre o conteúdo do ciclo celular. Conceitos desconexos e/ou respostas em branco predominaram sobre respostas com algum contexto/rigor científico empregado da forma correta, principalmente com os estudantes da Estadual tanto nas questões subjetivas (Figura 4 A) quanto nas objetivas (Figura 4 B). Segundo Krasilchik (2016), as dificuldades observadas no presente estudo podem ser resultantes do modelo meramente descritivo das disciplinas ministradas no ensino médio com uma grande quantidade de terminologias, que não estão vinculadas com a aplicação e/ou análise do funcionamento das estruturas a partir do uso de metodologias de ensino tradicionais.

A maior dificuldade na compreensão de conteúdos associados com as estruturas microscópicas no pré-teste pelos estudantes também foi relatada por Zierer (2017), o que reforça a dificuldade no ensino de conceitos abstratos, pois a maioria dos estudantes não consegue criar imagens dos processos biológicos, o que leva os mesmos a memorização de figuras nos livros didáticos. Além disso, outro desafio para o ensino é a presença de termos e processos que, a priori, se apresentam de forma desconexa com a observação cotidiana dos estudantes (Duré, et al., 2018). Dentro desse contexto, a biologia celular e a genética são disciplinas que possuem muita resistência dos estudantes durante o ensino médio, que pode estar associada a uma deficiência no aporte teórico dos estudantes, dificultando o 
estabelecimento de conexões (Silva \& Kalhil, 2017) como observado durante o pré-teste das questões subjetivas e objetivas nas três escolas.

As respostas subjetivas no pós-teste (Figura $4 \mathrm{C}$ ) mostrou que a EF e a EP apresentaram médias significativas maiores em todas as questões (individual e total), exceto a questão 5 da EF. O melhor desempenho da EF nas questões subjetivas pode estar relacionado às metodologias ativas de ensino que são frequentemente utilizadas na instituição. Por cursarem o ensino médio integrado ao técnico, é comum a participação em aulas práticas, tanto nas disciplinas profissionalizantes, quanto nas da base comum (Ramos, 2017). Segundo Krasilchik (2016), as questões subjetivas permitem que os estudantes apresentem respostas estruturadas, de forma que seja possível avaliar sua capacidade de sintetizar, compreender conceitos e analisar problemas como foi observado para os estudantes da EF. Para Trivelato e Tonidandel (2015), sequências de ensino investigativas devem contemplar a expressão através da linguagem e/ou da escrita, pois permitem que os estudantes possam comunicar e registrar o conhecimento adquirido.

No pós-teste (Figura 4 D), a EP obteve as melhores médias para as questões objetivas. O maior rendimento da EP pode estar associado ao fato desses estudantes estarem mais acostumados às metodologias de ensino tradicionais, em que há predominância de aulas expositivas com resolução de questões de múltipla escolha nos moldes do ENEM (Exame Nacional do Ensino Médio) e de outros vestibulares de forma mais frequente. Este fato corrobora com os resultados encontrados no pré-teste das questões objetivas (Figura 4 B), onde a EP obteve as melhores médias. Ressalta-se que a SEI serviu para aprimorar o conhecimento dos estudantes da EP sobre o ciclo celular, de uma forma mais dinâmica e interativa do que eles estão habituados.

Durante a aplicação da SEI, foi observada a modificação da percepção dos estudantes à medida que as metodologias propostas foram executadas. A partir das perguntas motivadoras e das discussões geradas entre os grupos e a professora foi possível construir o conhecimento de forma mais efetiva como observado no pós-teste (Figura 4 CD). Os estudantes ficaram muito interessados em responder às questões motivadoras, o que proporcionou a inserção deles em um ciclo investigativo, propondo hipóteses e discussões sobre a temática. Esta percepção corrobora com o que foi observado por Brito et al. (2018) onde, segundo os autores, a abordagem investigativa coloca o estudante como protagonista no processo ensino aprendizagem tendo a construção dos conhecimentos mediadas pelo professor que atua como orientador, fomentando discussões, explicações e viabilizando a sistematização do conhecimento. 
Para compreender o quanto a SEI contribuiu para o aprendizado dos estudantes sobre o ciclo celular foi realizado o cálculo do ganho normalizado de aprendizagem $(g)$ proposto por Hake (1998), a partir da porcentagem de acertos nos questionários pré e pós das questões subjetivas ou objetivas. O cálculo permitiu avaliar o quanto a turma progrediu na compreensão do conteúdo. Segundo esta avaliação, os estudantes da Federal apresentaram maior $g$ total para questões subjetivas e os da Particular para objetivas. Nas questões subjetivas, o $g$ total da EF, EE e EP foi alto $(g \geq 0,70)$, médio $(0,30 \leq g>0,70)$ e médio, respectivamente. $\mathrm{Na}$ análise individual, todas as questões subjetivas da $\mathrm{EF}$ apresentaram $g$ altos. $\mathrm{Na} \mathrm{EE}$, apenas as questões 1 e 5 apresentaram valores médio e alto, respectivamente, enquanto as outras questões apresentaram $g$ baixos $(\mathrm{g}<0,30)$. Na EP, as questões com $g$ altos foram: 1,5 e 7, as demais foram classificadas em médios. A questão 5 teve o maior $g$ na EF $(0,94), \mathrm{EE}(0,77)$ e na EP $(0,97)$ quando comparada com as outras questões (Tabela 1$)$.

Nas questões objetivas, o $g$ total das escolas EF, EE e EP foi considerado médio, médio e alto, respectivamente. A partir da análise das questões de forma individual, os valores de $g$ para a EF foram altos (1, 4, 5 e 7); médios (2 e 6) e baixo (apenas para a 3). Para a EE, o $g$ foi alto (apenas para a 5); médio (1, 4 e 6) e baixo (2, 3 e 7). Para a EP, os valores de $g$ foram altos para todas as questões, exceto para a 2 (valor médio). Em relação ao $g$ individual das questões subjetivas e objetivas, ressalta-se a questão 5 com o maior $g$ para cada tipo de questão para as três escolas. Tanto a EF quanto a EE mostraram dificuldades em responder à questão $3(g<0,30)$, mesmo após a aplicação das metodologias. A questão 5 apresentou os maiores valores de $g$ nas três escolas, corroborando com os dados da Figura 4 D, onde não houve diferença significativa entre as médias das respostas das três escolas. Os resultados de $g$ total confirmam que a escola EP obteve o melhor desempenho nas questões objetivas e a EF nas subjetivas, assim como observado no pós-teste (Figura $4 \mathrm{CD}$ ).

Os estudantes da EE apresentaram $g$ total e/ou individual baixo e menor para as questões subjetivas e objetivas (Tabela 1), o que reforça a maior dificuldade desses estudantes no pré e no pós-teste. Contudo, não podemos desconsiderar o bom rendimento da EE no pósteste em relação ao pré-teste, mostrando que a SEI aplicada foi eficiente para estes estudantes. Segundo Moul e Silva (2017), um dos conteúdos que mais causam confusões nos estudantes é o de divisão celular (mitose e meiose), devido à nomenclatura e similaridade dos processos que ocorrem em cada fase, como observados principalmente nos estudantes da EE. 
Tabela 1 - Percentual de acertos no pré-teste e pós-teste e ganho normalizado de aprendizagem (g) das escolas EF, EE e EP na cidade de Floriano-PI.

\begin{tabular}{|c|c|c|c|c|c|c|c|c|c|c|}
\hline \multirow[b]{2}{*}{ Questão } & \multirow[b]{2}{*}{ Número } & \multicolumn{3}{|c|}{ Federal (EF) } & \multicolumn{3}{|c|}{ Estadual (EE) } & \multicolumn{3}{|c|}{ Particular (EP) } \\
\hline & & $\begin{array}{l}\text { Pré- } \\
\text { teste }\end{array}$ & $\begin{array}{l}\text { Pós- } \\
\text { teste }\end{array}$ & $g$ & $\begin{array}{l}\text { Pré- } \\
\text { teste }\end{array}$ & $\begin{array}{l}\text { Pós- } \\
\text { teste }\end{array}$ & $g$ & $\begin{array}{l}\text { Pré- } \\
\text { teste }\end{array}$ & $\begin{array}{l}\text { Pós- } \\
\text { teste }\end{array}$ & $g$ \\
\hline \multirow{7}{*}{ Subjetiva } & 1 & 35,71 & 92,85 & 0,89 & 4,76 & 59,52 & 0,58 & 34,52 & 89,29 & 0,84 \\
\hline & 2 & 21,42 & 91,66 & 0,89 & 5,95 & 33,33 & 0,29 & 34,52 & 79,76 & 0,69 \\
\hline & 3 & 13,09 & 82,14 & 0,79 & 0,00 & 19,05 & 0,19 & 25,00 & 67,86 & 0,57 \\
\hline & 4 & 13,09 & 77,38 & 0,74 & 0,00 & 14,29 & 0,14 & 14,29 & 50,00 & 0,42 \\
\hline & 5 & 23,81 & 95,23 & 0,94 & 0,00 & 77,38 & 0,77 & 25,00 & 97,62 & 0,97 \\
\hline & 6 & 3,57 & 86,90 & 0,86 & 0,00 & 3,57 & 0,04 & 20,24 & 53,57 & 0,42 \\
\hline & 7 & 3,57 & 77,38 & 0,77 & 0,00 & 16,67 & 0,17 & 26,19 & 80,95 & 0,74 \\
\hline \multirow[t]{4}{*}{ Total } & & 16,33 & 86,22 & 0,84 & 1,53 & 31,97 & $\mathbf{0 , 3 1}$ & 25,68 & 74,15 & 0,65 \\
\hline & 1 & 9,52 & 76,19 & 0,74 & 4,76 & 42,86 & 0,40 & 38,10 & 95,24 & 0,92 \\
\hline & 2 & 9,52 & 57,14 & 0,53 & 0,00 & 14,29 & 0,14 & 14,29 & 57,14 & 0,50 \\
\hline & 3 & 14,28 & 38,09 & 0,28 & 0,00 & 23,81 & 0,24 & 33,33 & 80,95 & 0,71 \\
\hline \multirow[t]{4}{*}{ Objetiva } & 4 & 9,52 & 80,95 & 0,79 & 4,76 & 52,38 & 0,50 & 47,62 & 95,24 & 0,91 \\
\hline & 5 & 42,85 & 95,23 & 0,92 & 0,00 & 95,24 & 0,95 & 57,14 & 100,00 & 1,00 \\
\hline & 6 & 9,52 & 71,42 & 0,68 & 0,00 & 38,10 & 0,38 & 19,05 & 95,24 & 0,94 \\
\hline & 7 & 33,33 & 90,47 & 0,86 & 0,00 & 28,17 & 0,29 & 52,38 & 85,71 & 0,70 \\
\hline Total & & 18,37 & $\mathbf{7 2 , 7 9}$ & 0,67 & 1,36 & 41,50 & 0,41 & $\mathbf{3 7 , 4 1}$ & 81,63 & 0,71 \\
\hline
\end{tabular}

$g$ - Valores para ganho normalizado de aprendizagem, segundo Hake (1998): baixo $(g<0,30)$, médio $(0,30 \leq g<$ $0,70)$ e alto $(g \geq 0,70)$. Questões Subjetivas: 1 - esquema das estruturas celulares participantes do ciclo celular; 2 - definição de ciclo celular; 3 - características da mitose; 4 - características da intérfase e sua importância para o ciclo celular; 5 - fases do ciclo celular a partir da análise de figuras; 6 - células que realizam mitose no corpo humano e 7 - doenças relacionadas à mitose. Questões Objetivas: 1- fase do rompimento do envoltório nuclear; 2 - fase da duplicação dos cromossomos; 3 - fase da condensação dos cromossomos; 4 - estrutura envolvida na migração das cromátides irmãs; 5 - sequência das fases do ciclo celular; 6 - fase da formação da placa equatorial e 7 - estrutura responsável por promover a ligação do fuso mitótico aos cromossomos.

Fonte: Dados da pesquisa (2019).

O uso de modelos didáticos propostos por Silva et al. (2018) também permitiu a maior compreensão dos estudantes quanto ao ciclo celular. Neste estudo, os alunos puderam construir as etapas da divisão celular a partir da utilização da modelagem, representando a movimentação dos cromossomos com massa de modelar. Kieling et al. (2018) a partir do método da Engenharia Didática (ED) utilizaram um modelo didático sobre a molécula de DNA, o jogo didático "Trilha do Ciclo Celular" e a prática A. cepa para compor uma sequência didática para o ensino sobre o ciclo celular. Segundo os autores, aliar modelos e jogos didáticos às aulas possibilitou aos estudantes uma melhor compreensão da definição e do papel desempenhado pelas estruturas celulares, e que a partir da prática de A. cepa houve um melhor entendimento das fases da mitose e maior assimilação e aplicação dos conceitos.

Após a aplicação da SEI, os estudantes responderam a um questionário feedback (Figura $5 \mathrm{AB}$ ) para conhecer suas percepções quanto às metodologias empregadas. Não houve 
diferença significativa para cada tópico avaliado (metodologia, dificuldade, aprendizagem, interesse e satisfação) entre as três escolas e também não houve diferença entre o modelo didático e a prática de $A$. cepa para os tópicos avaliados.

Figura 5. Média das respostas do questionário feedback para o modelo didático (A) e para a prática de A. cepa (B) realizadas por 21 estudantes da EF, EE e EP na cidade de Floriano-PI. Os resultados referem-se à análise das notas ( 0 a 5 ) para 5 questões respondidas pelos estudantes das três escolas.

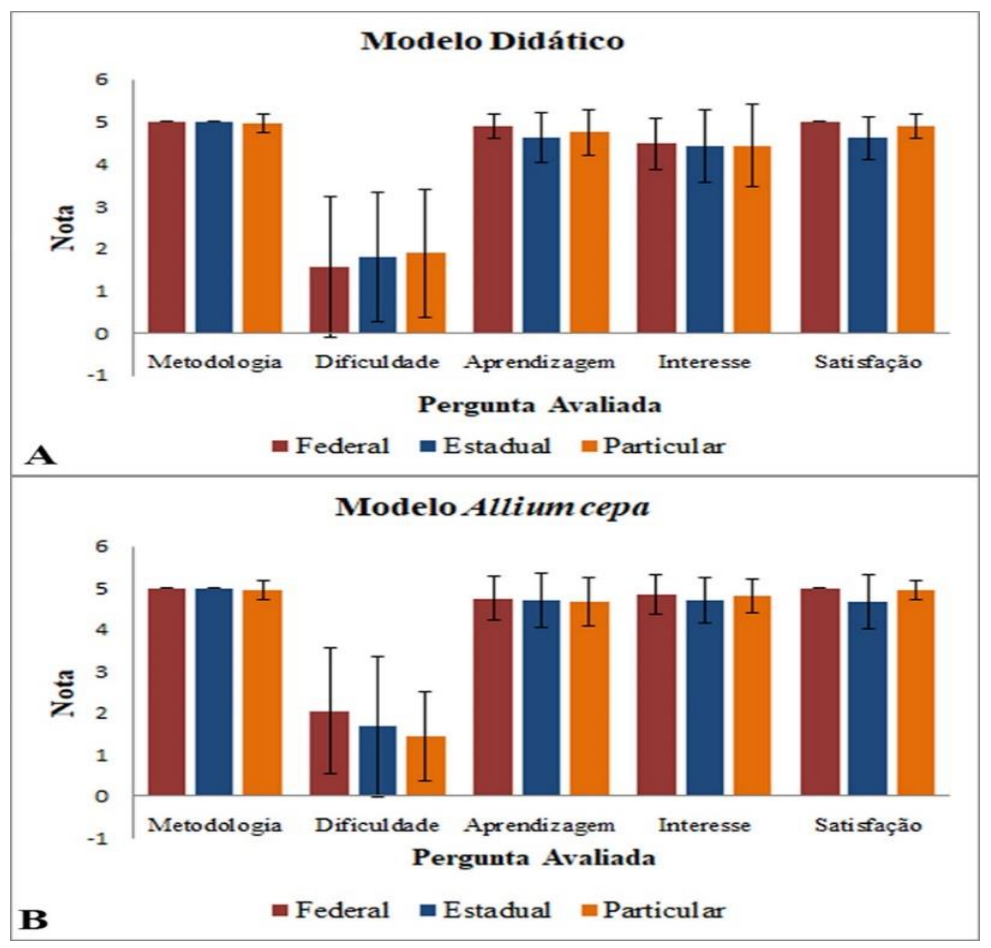

Fonte: Dados da pesquisa (2019).

Sendo assim, as metodologias empregadas permitiram aos estudantes observar, analisar e discutir sobre as respostas para as questões propostas, refletindo de forma positiva no questionário feedback. Portanto, verifica-se a necessidade de adoção de metodologias de ensino que viabilizem uma maior integração dos estudantes, entre si e com os professores, de forma que seja possível tornar conteúdos de difícil compreensão, como a divisão celular, mais acessível, prazeroso e significativo ao estudante (Miranda, 2017; Pereira \& Miranda, 2017).

\section{Considerações Finais}


Os resultados evidenciaram que os alunos das três escolas apresentaram dificuldades na compreensão do ciclo celular a partir da análise dos conhecimentos prévios e do pré-teste, principalmente, os alunos da escola Estadual. Durante a aplicação da SEI, foi possível observar o empenho e envolvimento dos alunos em buscar as respostas para as perguntas motivadoras a partir do uso das metodologias empregadas. O uso da SEI modificou a postura dos alunos tornando-os protagonistas na construção dos conhecimentos a partir da análise, reflexão e discussão das suas percepções sobre o conteúdo. Assim, constatou-se o aprendizado significativo sobre o ciclo celular nas três escolas no pós-teste. A partir dos valores de $g$ foi evidenciado a eficiência da SEI nas três escolas, mesmo para a EE que apresentou menor ganho de aprendizagem. Além disso, no questionário feedback, foi verificado que a SEI teve excelente aceitação pelos alunos como metodologia para o aprendizado do ciclo celular nas três escolas.

Assim, destaca-se a importante necessidade do uso de metodologias ativas incorporadas a sequência de ensino investigativa, similares às que foram propostas neste estudo nas escolas de ensino básico, principalmente naquelas em que há pouca infraestrutura, como as escolas Estaduais, para que os alunos possam atribuir maior significado aos conteúdos que estão sendo ensinados, superando o ensino meramente informativo, descontextualizado e fragmentado.

\section{Conflitos de Interesse}

Os autores declaram não existir conflitos de interesse.

\section{Referências Bibliográficas}

Ausubel, D. P. (2003). Aquisição e retenção de conhecimentos: uma perspectiva cognitiva. Coimbra: Plátano.

Ayres, M., Ayres, J. M., Ayres, D. L., \& Santos, A. S. (2007). Aplicações estatísticas nas áreas das ciênicas biomédicas. Retirado de https://www.mamiraua.org.br/ptbr/publicacoes/publicacoes/2007/livros/bioestat-50/

Barbosa, V. A. (2015). O ensino de Biologia na Educação de Jovens e Adultos: A concepção dos alunos sobre atividades investigativas e a percepção destes alunos a respeito das 
contribuições das atividades investigativas na aprendizagem da mitose e da meiose. Universidade Federal de Outro Preto.

Bianchi, J., Mantovani, M. S., \& Marin-Morales, M. A. (2015). ScienceDirect analysis of the genotoxic potential of low concentrations of Malathion on the Allium cepa cells and rat hepatoma tissue culture. JES - Journal of Environmental Sciences, 36, 102-111. Retirado de: https://doi.org/10.1016/j.jes.2015.03.034

Borges, T. S., \& Alencar, G. (2014). Metodologias ativas na formação crítica do estudante: o uso das metodologias ativas como recurso na formação crítica do estudante do ensino superior. Cairu Em Revista, 3(4), 119-143.

Braga, C. M. D. D. S., Gastal, M. L. D. A., \& Ferreira, L. B. D. M. (2010). O Uso de Modelos em Uma Sequência Didática Para o Ensino dos Processos da Divisão Celular (Vol. 5). Universidade de Brasília.

Brito, B. W. D. C. S., Brito, L. T. S., \& Sales, E. D. S. (2018). Ensino por investigação: uma abordagem didática no ensino de ciências e biologia. Revista Vivências Em Ensino de Ciências, 2(1), 54-60.

Carneiro, S. P., \& Silva, J. da. (2007). O Teste Allium cepa no ensino de Biologia Celular : um estudo de caso com alunos da graduação. Acta Scientiae, 9 (June 2015).

Cobalchini, M. G. (2016). Elaboração de aulas práticas investigativas de Citologia para alunos do primeiro ano do Ensino Médio. Os Desafios Da Escola Pública Paranaense Na Perspectiva Do Professor PDE.

Duré, R. C., Andrade, M. J. D. de, \& Abílio, F. J. P. (2018). Ensino de Biologoa e contextualização do conteúdo: quais temas o aluno de ensino médio relaciona com o seu cotidiano? Experiencias Em Ensino de Ciências, 13(1), 259-272.

Fernandes, M. G., Vaini, J. O., Crispim, B. do A., \& Teixeira, T. Z. (2017). Práticas de biologia celular (C. C. Acadêmicos, Ed.). Dourados, MS: UFGD Editora. 
Garofalo, D. (2018). Como as metodolgoias de ensino favorecem o aprendizado. Retrieved March 28, 2018, Retirado de Revista Nova Escola website:

https://novaescola.org.br/conteudo/11897/como-as-metodologias-ativas-favorecem-oaprendizado

Gonçalves, R. R., Martello, A. R., Epple, B., Laurence, C., Desbessel, J., \& Post, P. (2014). Bingo da célula: uma ferramenta metodológica para o ensino de biologia celular. Ensino \& Pesquisa, 12(1).

Griffin, V., Mcmiller, T., Jones, E., \& Johnson, C. M. (2003). Identifying novel-helix-loophelix in Caenorhabditis elegans through a classrom demonstration of functional genomics. Cell Biology Education, 2(1).

Hake, R. R. (1998). Interactive-engagement versus traditional methods: A six-thousandstudent survey of mechanics test data for introductory physics courses. American Journal of Physics, 66(1), 64-74. Retirado de: https://doi.org/10.1119/1.18809

Kieling, K. M. C., Goulart, A. da S., \& Roehrs, R. (2018). Ciclo celular : construção e validação de uma sequência didática pela metodologia da engenharia didática. Journal of Biochemistry Education, 16(2).

Krasilchik, M. (2016). Prática de Ensino em Biologia (4ª). São Paulo: Editora da Universidade de São Paulo.

Krug, R. D. R., Vieira, M. S. M., Maciel, M. V. D. S. E., Erdmann, T. R., Vieira, F. C. D. F., Koch, M. C., \& Grosseman, S. (2016). O “bê-á-bá” da aprendizagem baseada em equipe. Revista Brasileira de Educação Médica, 40(4), 602-610.

Leão, G. M. C., \& Randi, M. A. F. (2017). Existe vida além da aula expositiva? um caso para a biologia celular. EDUCERE:XII Ccongresso Nacional de Educação.

Luo, P. (2012). Creating a Double-Spring Model to Teach Chromosome Movement during Mitosis \& Meiosis Development of Materials Evaluation \&. The American Biology Teacher, 74(4), 266-269. Retirado de: https://doi.org/10.1525/abt.2012.74.4.11 
Macedo, K. D. D. S., Acosta, B. S., Silva, E. B. da, Souza, N. S. de, Beck, C. L. C., \& Silva, K. K. D. da. (2018). Metodologias ativas de aprendizagem: caminhos possíveis para inovação no ensino em saúde. Escola Anna Nery, 22(3), 1-9. Retirado de: https://doi.org/10.1590/21779465-EAN-2017-0435

Miranda, E. S. D. A. (2017). A experimentação no ensino de Biologia: contribuições da teoria do ensino desenvolvimental para a formação do pensamento teórico. Universidade Federal de Goiás.

Monteiro, J. D. S., \& Silva, D. P. da. (2015). A influência da estrutura escolar no processo de ensino-aprendizagem : uma análise baseada nas experiências do estágio supervisionado em Geografia. Ensino e Geografia, 19(3), 19-28. Retirado de:

https://doi.org/10.5902/2236499414315

Moul, R. A. T. D. M., \& Silva, F. C. da. (2017). A modelização em genética e biologia molecular: ensino de mitose com massa de modelar. Experiencias Em Ensino de Ciências, $12(2)$.

Peixe, P. D., Pinheiro, L. G., Araújo, M. F. F., \& Moreira, S. A. (2017). Os temas DNA e Biotecnologia em livros didáticos de biologia : abordagem em ciência , tecnologia e sociedade no processo educativo. Acta Scientiae, 19(1), 177-191.

Pereira, M. B., \& Miranda, A. F. de. (2017). O ensino de mitose para a geração Z: uma análise entre dois métodos. Revista Prática Docente, 2(2), 255-269.

Porto, M., Rizowy, G. M., \& Cezar, S. (2015). Metodolgoias alternativas para o ensino de biologia celular e molecular para o ensino básico. Revista Ampliar, 2(2), 1-12.

Ramos, M. N. (2017). Ensino Médio na Rede Federal e nas Redes Estaduais : por que os estudantes alcançam resultados diferentes nas avaliações de larga escala ? Holos, 02. Retirado de: https://doi.org/10.15628/holos.2018.6976

Scarpa, D. L., \& Campos, N. F. (2018). Potencializades do ensino de Biologia por 
investigação. Estudos Avançados, 32(94), 25-42. Retirado de: https://doi.org/10.1590/s010340142018.3294 .0003

Silva, C. C. da, \& Kalhil, J. B. (2017). A aprendizagem de genética à luz da Teoria Fundamentada : um ensaio preliminar. Ciência \& Educação, 23(1), 125-140.

Silva, J. da, \& Andrade Neto, A. S. de. (2004). DNA \& ambiente: uso do ensaio cometa como ferramenta para discussão interdisciplinar de lesão e reparo do DNA na pó-s graduação em ensino de ciências. IV Encontro Nacional e Pesquisa Em Educação Em Ciências, 1-13.

SilvA, T. R. da, Silva, B. R. da, \& Silva, B. M. P. da. (2018). Modelização didática como possibilidade de aprendizagem sobre divisão celular no ensino fundamental. Revista Thema, 15(4), 1376-1386.

Tanajura, V. S. (2017). Dificuldades no ensino de Biologia Celular na escola de educação média: considerações e apontamentos a partir de depoimentos de professores(as). Universidade Estadual Paulista.

Trivelato, S. L. F., \& Tonidandel, S. M. R. (2015). Ensino por investigação: eixos organizadores para sequências de ensino de biologia. Revista Ensaio, 17, 97-114.

Vinholi-Júnior, A. J., \& Princival, G. C. (2014). Modelos didáticos e mapas conceituais: biologia celular e as interfaces com a informática em cursos técnicos do IFMS. Holos, 02, $110-122$.

Wons, J. R. (2012). A atividade prática como feramenta para abordagem do ciclo celular nas células somáticas. O Professor PDE e Os Desafios Da Escola Pública Paranaense, 2.

Zierer, M. de S. (2017). The construction and application of didactic models in Biochemistry teaching. Journal Os Biochemistry Education, 15. Retirado de: https://doi.org/10.16923/reb.v15i0.691 
Research, Society and Development, v. 9, n. 9, e611997801, 2020

(CC BY 4.0) | ISSN 2525-3409 | DOI: http://dx.doi.org/10.33448/rsd-v9i9.7801

Porcentagem de contribuição de cada autor no manuscrito

Michelle Mara de Oliveira Lima - 50\%

Thâmara Chaves Cardoso - 10\%

Francisco Soares Santos Filho - 10\%

Francielle Alline Martins - 10\%

Pedro Marcos de Almeida - 20\% 